\title{
COMPARISON OF CAVITATION EROSION TEST RESULTS FROM VENTURI AND VIBRATORY FACILITIES
}

\author{
JU-GEN HE* and F. G. HAMMITT
}

Cavitation and Multiphase Flow Laboratory, Department of Mechanical Engineering and Applied Mechanics, University of Michigan, Ann Arbor, MI 48109 (U.S.A.)

(Received April 6, 1981)

\section{Summary}

A detailed comparison of cavitation erosion performance in tap water for five alloys in a vibratory (no-flow) system and a Venturi (flow) system was made. The effects of temperature variation $\left(80-200^{\circ} \mathrm{F}\right)$, Venturi throat velocity ( $34-49 \mathrm{~m} \mathrm{~s}^{-1}$ ) and vibratory horn double amplitude were studied. Correlations between maximum erosion rate (maximum mean depth of penetration rate $\left(\mathrm{MDPR}_{\max }\right)$ ) and incubation period IP, and the material mechanical properties Brinell hardness and ultimate resilience UR $=\mathrm{UTS}^{2} / 2 E$ (where UTS is the ultimate tensile strength and $E$ is the elastic modulus), were examined. Only moderate success was achieved in correlations between "erosion resistance" MDPR ${ }_{\max }{ }^{-1}$ and IP and these mechanical properties. However, a good correlation was found between MDPR $\mathrm{max}_{\max }$ and IP, pertinent to both facilities, of the form $\mathrm{MDPR}_{\max }{ }^{-1}=a \mathrm{IP}^{n}$, where $n$ is near unity (0.94). The cavitation intensity, as measured by MDPR $\mathrm{max}_{\max }$, was found to be 10. 20 times greater in the vibratory system, depending on horn amplitude and material. This ratio varies between 5 and 30 if individual materials are considered separately, being greatest for 1018 carbon steel and least for 316 stainless steel. This indicates the important differences in form between these cavitating regimes and the imprecision of material comparisons made in both regimes.

\section{Introduction}

Laboratory facilities for the investigation of cavitation erosion can be of various types such as vibratory, rotating disk or some form of restricted flow device such as a Venturi system, of which several types exist (see, for example, refs. 1 - 4). These can be divided into two categories, i.e. flowing and static. The vibratory facility [1 - 4], which is a non-flow device, is

\footnotetext{
*Permanent address: National Academy of Space Technology, Beijing, China.
} 
certainly the most common and the most economical. However, it is difficult to relate results from vibratory tests to flowing systems, either laboratory or field machines, because of the lack of the commonly used flow parameters such as velocity, Reynolds number, cavitation $\sigma$ parameter etc. Nevertheless, the vibratory cavitation erosion device is the unly cavitation erosion test so far standardized [4]. It is the purpose of this article to assist in relating vibratory cavitation results to flow results by comparing vibratory data with data from a Venturi system [1 - 3] at the University of Michigan using the same specimen material set of five alloys and the same water temperatures.

The materials used (the same bar stocks for both facilities) were 2024-T-4 and soft (1100-0) aluminum, 1018 carbon steel, 316 stainless steel and $3 \% \mathrm{C}$ common cast iron. Their mechanical properties are listed in Table 1 . The test temperatures included 80,160 and $200^{\circ} \mathrm{F}(27,71$ and $93{ }^{\circ} \mathrm{C}$ ), but only the lower two temperatures have been used so far in the Venturi system. The Venturi throat velocities were 36.3 and $49 \mathrm{~m} \mathrm{~s}^{-1}$. While only typical data are included here, detailed results can be found in ref. 8 , and related information can be found in refs. 9 and 10.

TABLE 1

Material mechanical properties

\begin{tabular}{llllcc}
\hline Alloy & $\begin{array}{l}\text { UTS } \\
\left(\times 10^{-3} \mathrm{lbf} \mathrm{in}^{-2}\right)\end{array}$ & $\begin{array}{l}E \\
\left(\times 10^{-6} \mathrm{lbf} \mathrm{in}^{-2}\right)\end{array}$ & $\begin{array}{l}\rho \\
\left(\mathrm{g} \mathrm{cm}^{-3}\right)\end{array}$ & $\begin{array}{l}\text { UR } \\
\left(\mathrm{lbf} \mathrm{in}^{-2}\right)\end{array}$ & $\begin{array}{l}\text { Hardness } \\
(\mathrm{HB})\end{array}$ \\
\hline Al 1100-0 & 11 & 10 & 2.71 & 6.1 & 41 \\
Al 2024-T-4 & 60 & 10.6 & 2.77 & 170 & 78 \\
1018 carbon steel & 70 & 30.0 & 7.85 & 81.7 & $120^{\mathrm{a}}$ \\
& & & & & $110.5^{\mathrm{b}}$ \\
316 stainless steel & 81.25 & 29.0 & 7.91 & 114 & 134 \\
Cast iron (3\% C) & 32.5 & 15.5 & 7.29 & 34.1 & 184 \\
\hline
\end{tabular}

UTS, ultimate tensile strength; $E$, elastic modulus; $\rho$, density; UR, ultimate resilience (UR = UTS $2 / 2 E)$.

Aluminum properties were taken from ref. 5 ; cast iron and carbon steel properties were taken from ref. $6 ; 316$ stainless steel properties were taken from ref. 7 .

a American, not annealed.

b Japanese, annealed.

\section{Description of the facilities}

\subsection{Vibratory facility}

The University of Michigan vibratory cavitation facility is shown in

Fig. 1. It includes a $20 \mathrm{kHz}$ resonant frequency piezoelectric drive and an amplifying horn. Double amplitudes (peak-to-peak) of $1.0 \times 10^{-3}, 1.38 \times$ $10^{-3}, 1.78 \times 10^{-3}$ and $2.0 \times 10^{-3}$ in $(25.4,35.1,45.2$ and $50.8 \mu \mathrm{m})$ were used. By using a steel vessel we can apply hydrostatic pressure to the liquid 


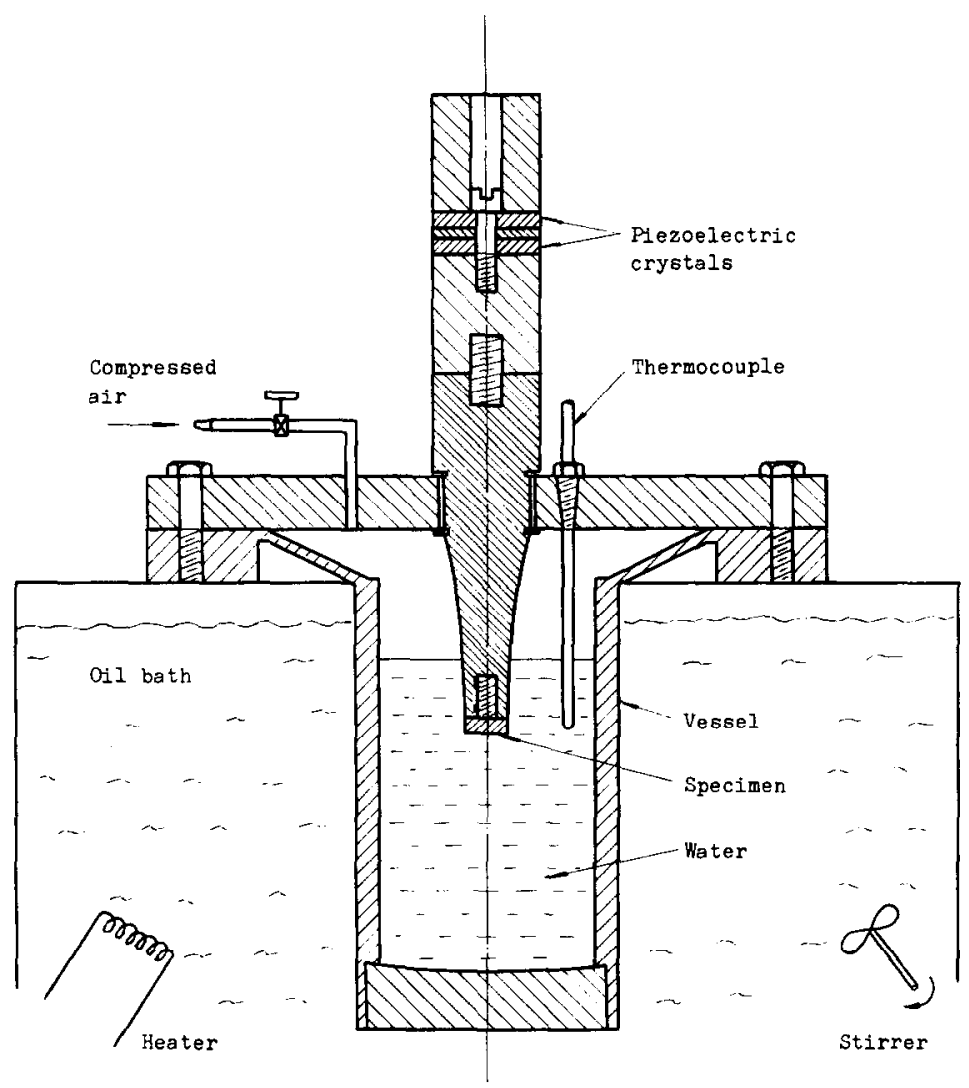

Fig. 1. Vibratory system.

and also control the temperature. In some of the tests we used a glass beaker of $1000 \mathrm{~cm}^{3}$ volume at $80^{\circ} \mathrm{F}\left(27^{\circ} \mathrm{C}\right)$ under atmospheric pressure, but the change of vessel is not important. For the higher temperatures the air suppression pressure was 1 bar. The specimen diameter was 9/16 in $(14.3 \mathrm{~mm})$. In all cases the specimens were fabricated from the same bar stock so that the mechanical properties were the same for the same material. Table 1 contains the material properties and Tables $2-4$ contain the results of these tests according to the horn double amplitudes.

\subsection{Venturi facility}

The cavitation erosion Venturi tests were done here in a high speed cavitation tunnel [1 - 3]. The Venturi Plexiglas test section is shown in Fig. 2. The throat diameter is $12.7 \mathrm{~mm}(0.510 \mathrm{in})$. The throat velocity is controlled by the pump speed and the downstream pressure, which is controlled by a surge tank. The maximum throat velocity is about $50 \mathrm{~m} \mathrm{~s}^{-1}$. Two throat velocities ( 36.3 and $49 \mathrm{~m} \mathrm{~s}^{-1}$ ) and two water temperatures (80 and $160^{\circ} \mathrm{F}$ ) were used. A higher temperature is not possible with a Plexiglas Venturi facility (the Plexiglas is necessary for visibility). Two erosion spec- 


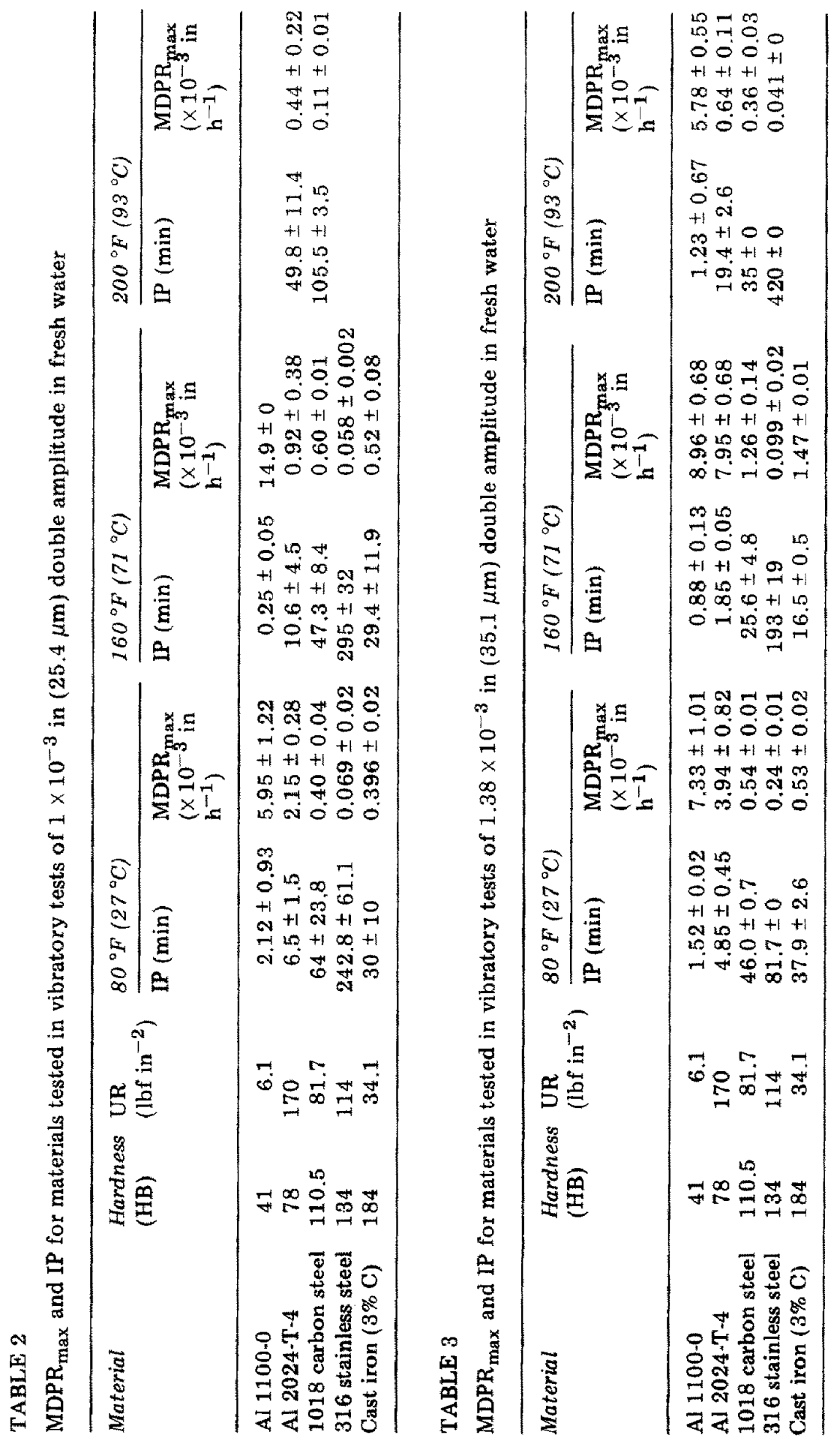




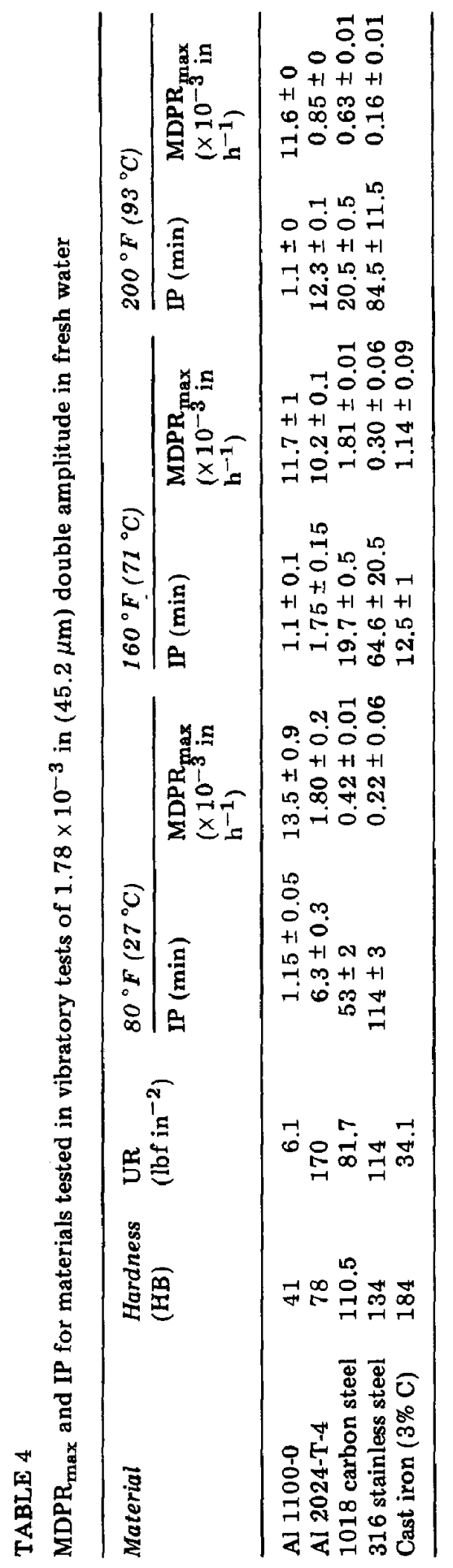


imens $(6.35 \mathrm{~mm}$ diameter) were inserted so that they were flush with the Venturi diffuser wall in the same axial plane (Fig. 2). The visual termination plane of the cavitation cloud is the same plane in the present tests. Table 5 summarizes the Venturi erosion results.

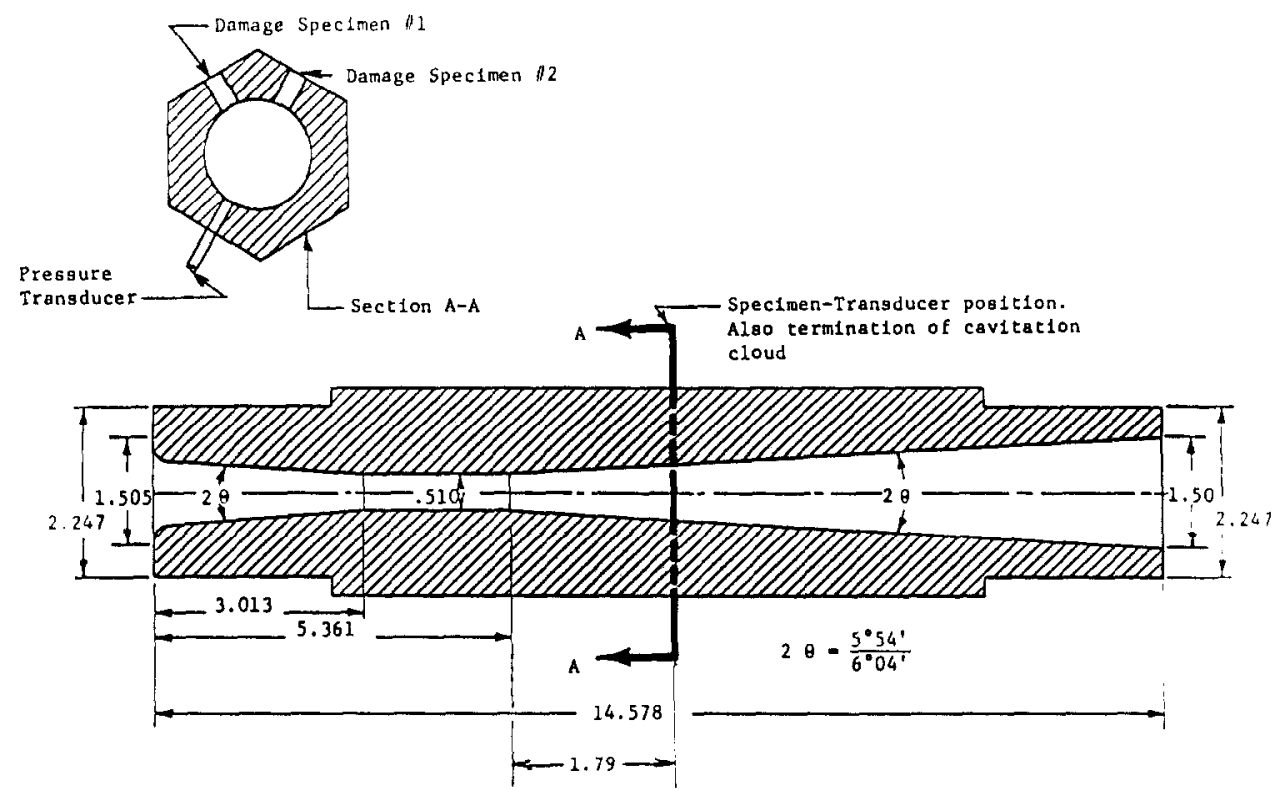

Fig. 2. Erosion Venturi system (all dimensions are given in inches).

The cavitation number $K$ (or $\sigma$ ) is the non-dimensional parameter which has generally been used $[1,2]$ to correlate cavitating flow regimes. In the present tests

$$
K=\frac{P-P_{\mathrm{v}}}{\frac{1}{2} \rho V^{2}}
$$

where $P$ is the pressure immediately downstream from the test section, $P_{\mathrm{v}}$ is the vapor pressure, $V$ is the throat velocity and $\rho$ is the liquid density. For the present tests, $K=0.62-0.64$ for $V=49 \mathrm{~m} \mathrm{~s}^{-1}$ and $K=0.73-0.76$ for $V=36.3 \mathrm{~m} \mathrm{~s}^{-1}$. Thus a velocity "scale effect" exists in these tests.

\section{Test results}

\subsection{Erosion rate and incubation period}

\subsubsection{General}

After an initial very small weight loss there is generally a period called the incubation period (IP) during which only relatively little material is removed. Thereafter, more rapid erosion occurs. Figure 3 shows the typical 


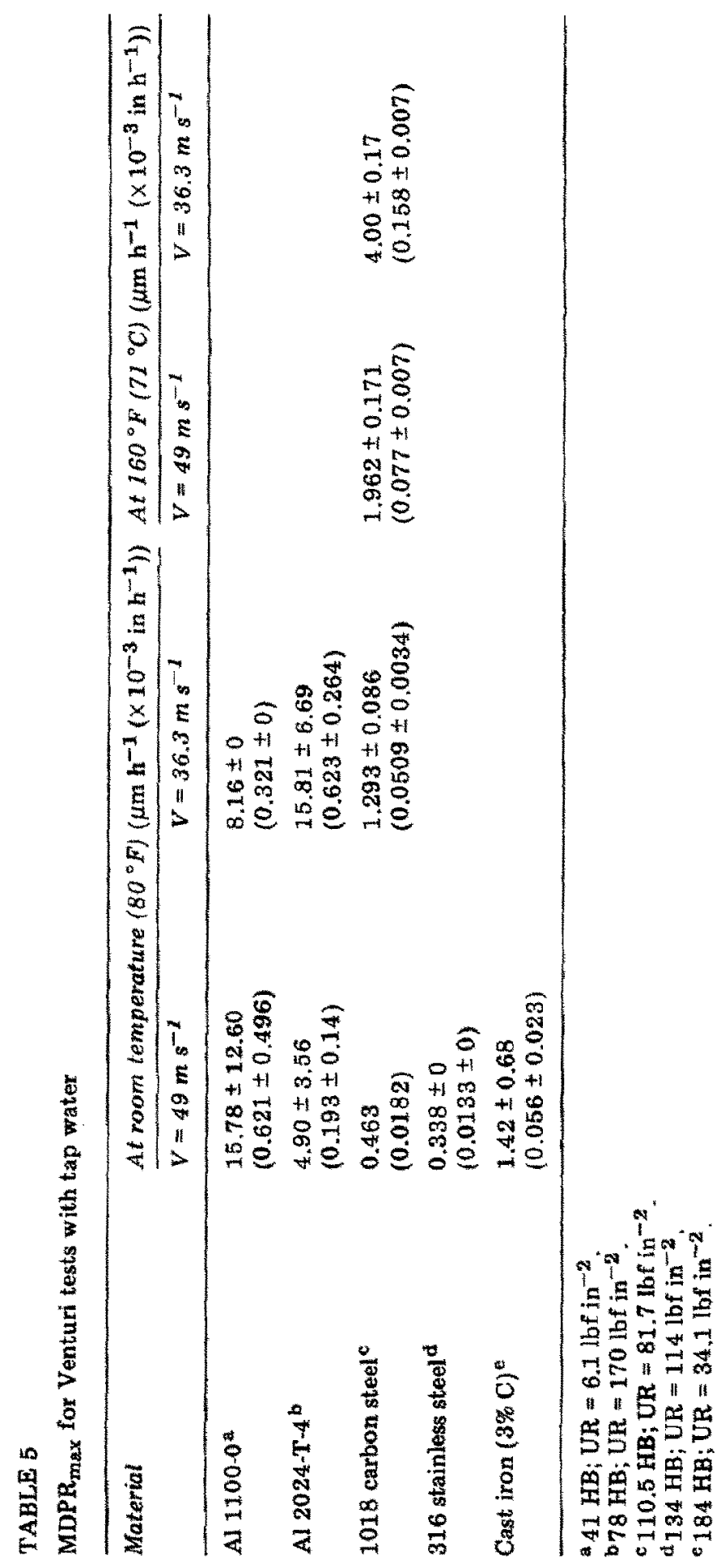




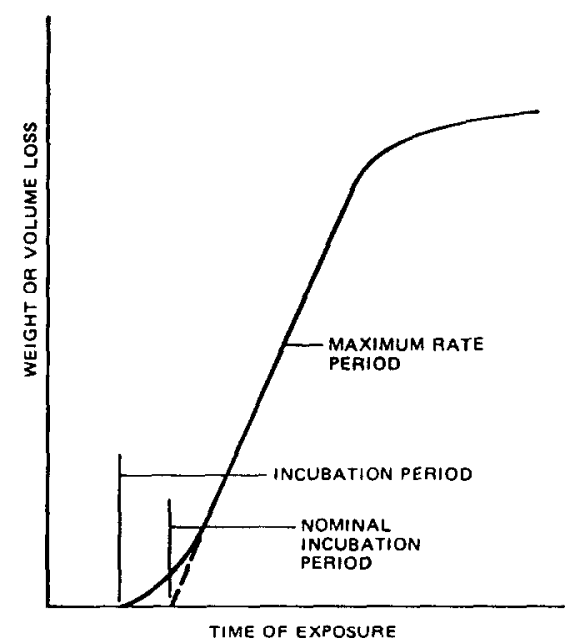

Fig. 3. A typical cavitation or liquid impact S-shaped erosion curve.

"S-shaped" erosion curve $[1,2,11,12]$. However, this characteristic curve was often not obtained in the present tests. Figure 4 is a typical newly measured mean depth of penetration rate (MDPR) versus time curve from the Venturi facility, while Figs. 5 and 6 are typical curves of weight loss versus cumulative time from the vibratory facility. (The MDPR is the volume loss rate per unit exposed area or the mean erosion depth per unit time.) The Venturi curve (Fig. 4) shows an initial MDPR peak followed by numerous subsequent peaks rather than the S-shaped curve (Fig. 3 ). The results of most

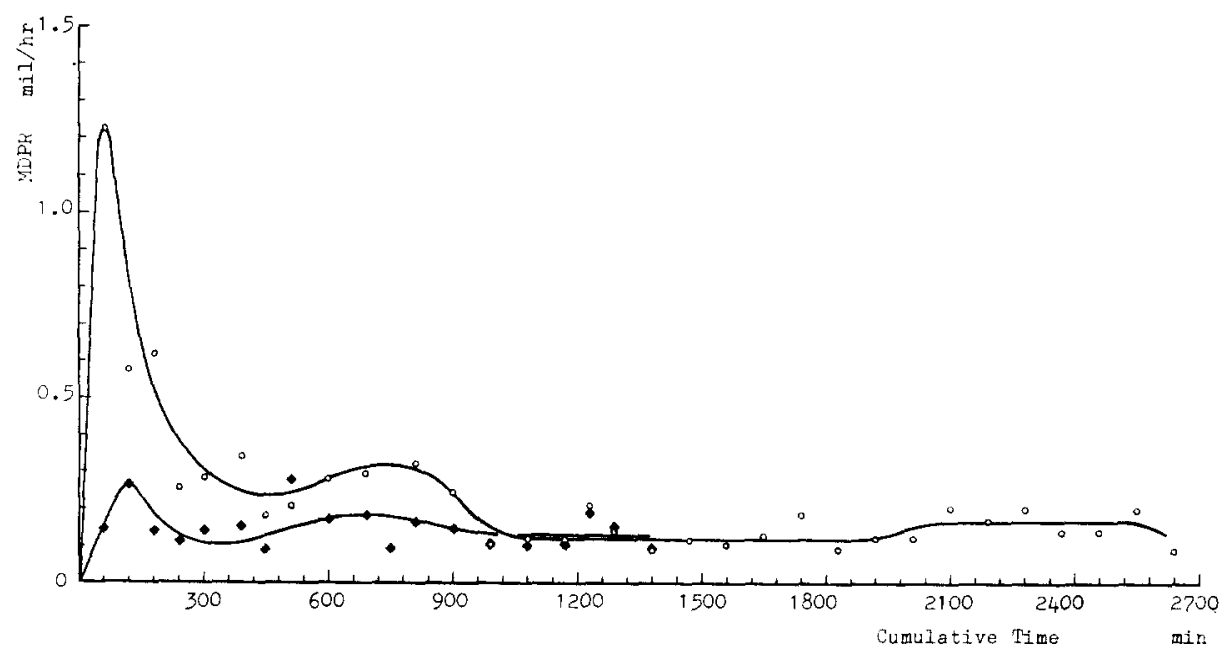

Fig. 4. MDPR vs. exposed time for the Al 1100-0 Venturi cavitation erosion test (throat velocity, $\left.49 \mathrm{~m} \mathrm{~s}^{-1}\left(160.8 \mathrm{ft} \mathrm{s}^{-1}\right)\right): 0$, specimen $4 ; \bullet$, specimen 3 . 


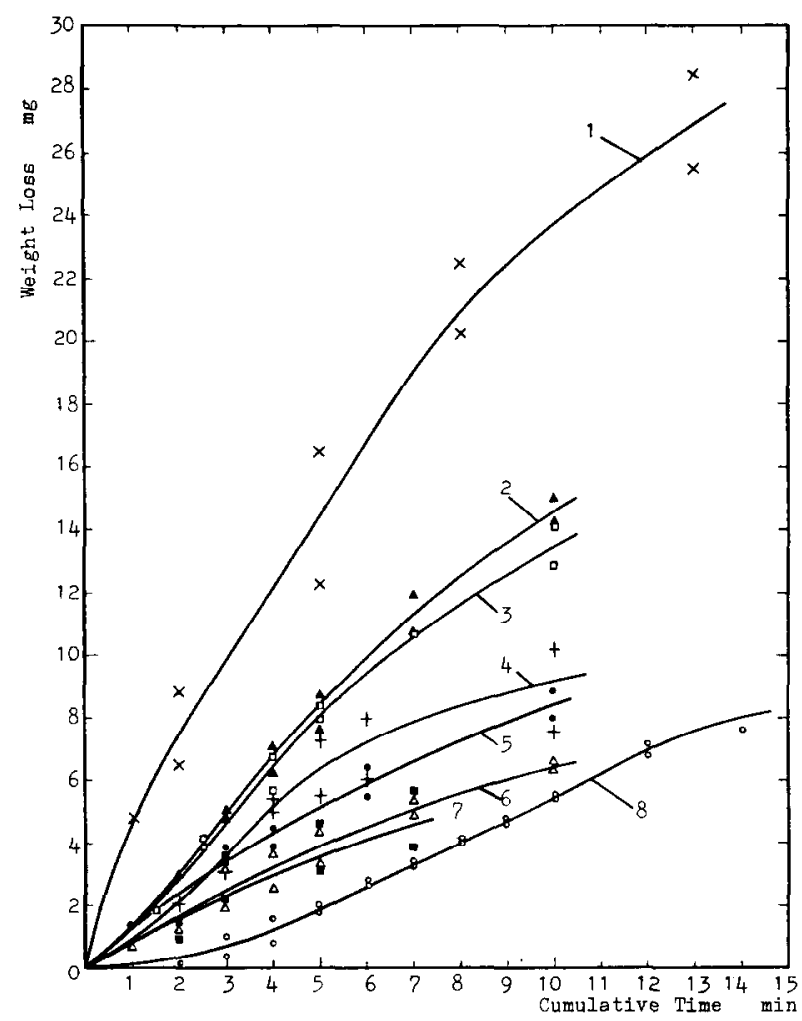

Fig. 5. Weight loss $v$ s. test time for Al 1100-0 vibratory cavitation erosion tests in fresh water at 1 bar: curve $1,1 \times 10^{-3}$ in $(25.4 \mu \mathrm{m}), 160^{\circ} \mathrm{F}\left(71^{\circ} \mathrm{C}\right), 14.7 \mathrm{lbf}$ in ${ }^{-2}$; curve 2 , $1.78 \times 10^{-3}$ in $(45.2 \mu \mathrm{m}), 160^{\circ} \mathrm{F}, 19.5 \mathrm{lbf}^{-2}$; curve $3,1.78 \times 10^{-3} \mathrm{in}, 80^{\circ} \mathrm{F}, 14.7 \mathrm{lbf}$ in $^{-2}$; curve $4,1.78 \times 10^{-3}$ in, $200^{\circ} \mathrm{F}\left(93^{\circ} \mathrm{C}\right), 26.2 \mathrm{lbf}^{-2}$; curve $5,1.38 \times 10^{-3}$ in $(35.1 \mu \mathrm{m}), 160^{\circ} \mathrm{F}, 19.5 \mathrm{lbf}^{-2}$; curve $6,1.38 \times 10^{-3} \mathrm{in}, 80^{\circ} \mathrm{F}, 14.7 \mathrm{lbf}$ in ${ }^{-2}$; curve 7 , $1.38 \times 10^{-3}$ in, $200^{\circ} \mathrm{F}, 26.2 \mathrm{lbf}^{-2}$; curve $8,1 \times 10^{-3}$ in, $80^{\circ} \mathrm{F}, 14.7 \mathrm{lbf}$ in $^{-2} ; x$, specimens 1 and $2 ; \triangle$, specimens 9 and $14 ; \square$, specimens 5 and $6 ;+$, specimens 3 and $10 ; \bullet$, specimens 7 and $13 ; \Delta$, specimens 4 and $7 ; \bullet$, specimens 1 and $2 ; \circ$, specimens 1 and 2 .

of the present tests for the ferrous alloys approach the S-shaped curve more closely.

\subsubsection{Incubation period}

The IP is defined here as the time required to obtain a mean depth of penetration (MDP) of $0.1 \times 10^{-3}$ in $(2.54 \mu \mathrm{m})$. Table 6 contains the IPs for both Venturi and vibratory tests. The IP for both facilities increases with hardness (except for cast iron). For the Venturi facility the IPs are much larger than for the vibratory facility. The magnitudes of the ratio $\mathrm{IP}_{\text {venturi }} /$ $\mathrm{IP}_{\text {vibratory }}$ vary from 2 to 27 , depending on the materials and test conditions (i.e. the velocities and amplitudes). For systems made from the same material the range is reduced. 


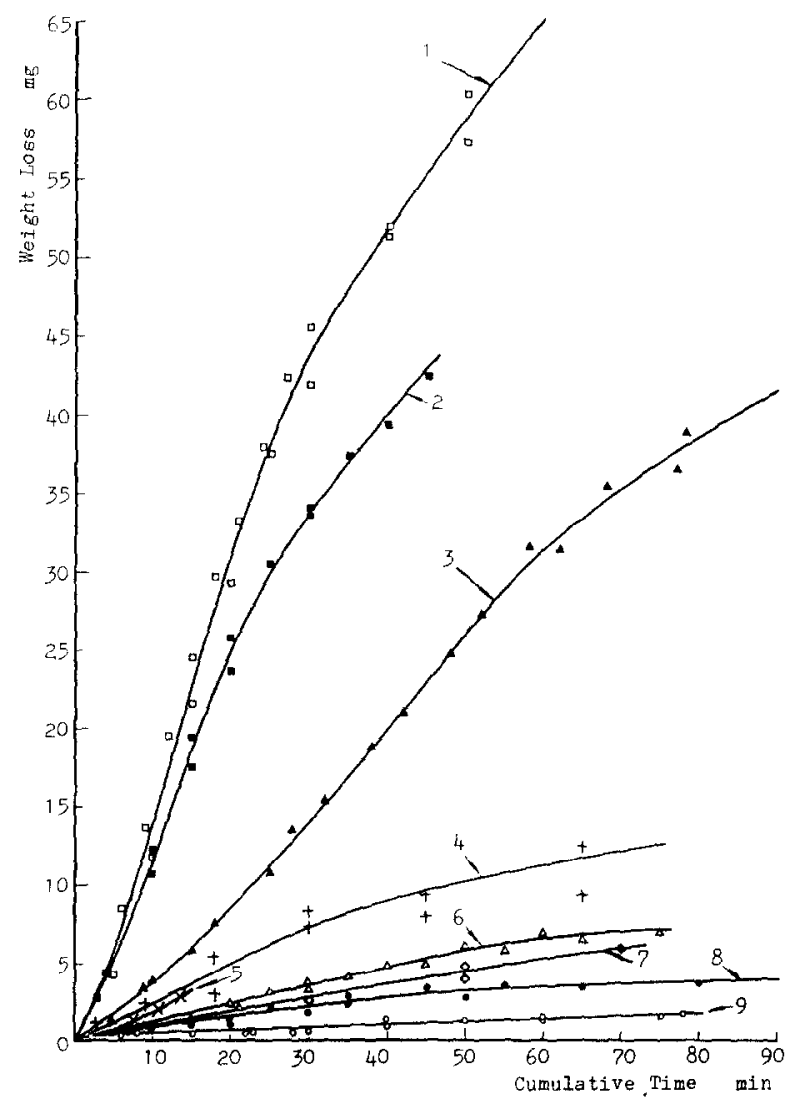

Fig. 6. Weight loss us. test time for the $\mathrm{Al}$ 2024-T-4 vibratory cavitation erosion tests in fresh water at 1 bar: curve $1,1.78 \times 10^{-3}$ in $(45.2 \mu \mathrm{m}), 160^{\circ} \mathrm{F}\left(71^{\circ} \mathrm{C}\right), 19.5 \mathrm{lbf}^{-2}$; curve $2,1.38 \times 10^{-3}$ in $(35.1 \mu \mathrm{m}), 160^{\circ} \mathrm{F}, 19.5 \mathrm{lbf}$ in ${ }^{-2}$; curve $3,1.38 \times 10^{-3} \mathrm{in}, 80^{\circ} \mathrm{F}$ $\left(27^{\circ} \mathrm{C}\right), 14.7 \mathrm{lbf}^{-2}$; curve $4,1 \times 10^{-3}$ in, $80^{\circ} \mathrm{F}, 14.7 \mathrm{lbf}$ in ${ }^{-2}$; curve $5,1.78 \times 10^{-3}$ in, $80^{\circ} \mathrm{F}, 14.7 \mathrm{lbf}^{-2}$; curve $6,1.78 \times 10^{-3} \mathrm{in}, 200^{\circ} \mathrm{F}\left(93^{\circ} \mathrm{C}\right), 26.2 \mathrm{lbf}^{-2}$; curve $7,1 \times$ $10^{-3}$ in, $160^{\circ} \mathrm{F}, 14.7 \mathrm{lbf}$ in -2 ; curve $8,1.38 \times 10^{-3}$ in, $26.2 \mathrm{lbf} \mathrm{in}^{-2}, 200^{\circ} \mathrm{F}$; curve $9,1 \times$ $10^{-3}$ in, $200^{\circ} \mathrm{F}, 26.2 \mathrm{lbf}$ in $-2 ; \circ$, specimens 5 and $6 ; \omega$, specimens 7 and $8 ; \Delta$, specimens 4 and $12 ;+$, specimens 4 and $5 ; x$, specimens 14 and $15 ; \Delta$, specimens 11 and $13-1 ; 0$, specimens 9 and $12 ; \bullet$, specimens 10 and $13-2 ; \diamond$, specimens 7 and 8 .

\subsubsection{Maximum erosion rate}

$\mathrm{MDPR}_{\max }$ is the maximum value that occurs during the test period. Figure 4 shows typical curves for soft (1100-0) aluminum. Table 7 contains $M D P R_{\max }$ values from both Venturi and vibratory facilities for all tests and the ratio $M D P R_{\text {max vibratory }} / M P_{\max }$ venturi. MDPR $_{\max }$, as expected, decreases with increased hardness except for cast iron. MDPR $R_{\max }$ values for vibratory runs are much larger than the values for Venturi runs. As shown in Tables 8 and 9, the average ratios depend on the horn amplitude and of course on the Venturi velocity. The averages range from 11 to 18. 


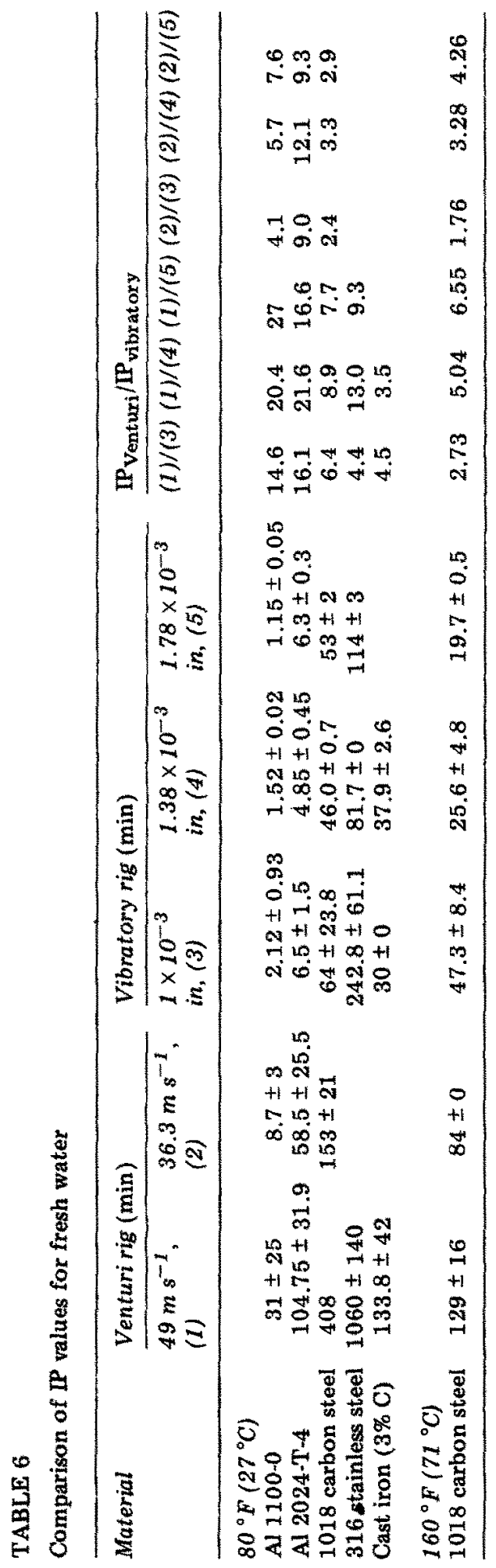




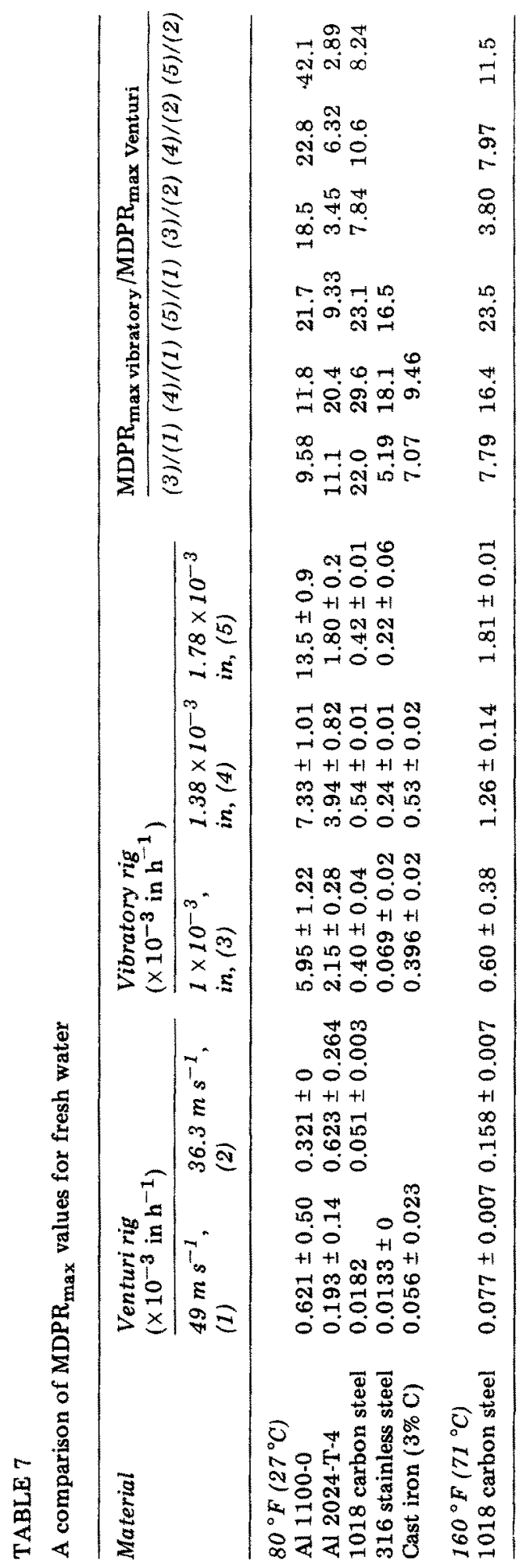


TABLE 8

The ratio $M D P R_{\max }$ vibratory $: M D P R_{\max }$ Venturi for $80^{\circ} \mathrm{F}$ tap water

\begin{tabular}{lllc}
\hline Material & \multicolumn{2}{c}{ MDPR $_{\max }$} & \multicolumn{2}{c}{ MDPR $_{\text {max vibratory }}$ : } \\
\cline { 2 - 3 } & Vibratory $^{\mathrm{a}}$ & Venturi $^{\mathrm{b}}$ & \\
\hline Al 1100-0 & $5.95 \pm 1.22$ & $0.621 \pm 0.50$ & 9.58 \\
Al 2024-T-4 & $2.15 \pm 0.28$ & $0.193 \pm 0.14$ & 11.14 \\
1018 carbon steel & $0.40 \pm 0.04$ & 0.0182 & 21.98 \\
316 stainless steel & $0.069 \pm 0.02$ & $0.0133 \pm 0$ & 5.19 \\
Cast iron (3\% C) & $0.396 \pm 0.02$ & $0.056 \pm 0.023$ & 7.07 \\
Numerical average & & & $11.0_{-5.8}^{+11.0}$ \\
\hline
\end{tabular}

a $1 \times 10^{-3}$ in at 1 bar.

${ }^{b} V=49 \mathrm{~m} \mathrm{~s}^{-1}$.

TABLE 9

The ratio $M D P R_{\max }$ vibratory $: M D P R_{\max }$ Venturi for $80^{\circ} \mathrm{F}$ tap water

\begin{tabular}{|c|c|c|c|}
\hline \multirow[t]{2}{*}{ Material } & \multicolumn{2}{|l|}{$\mathrm{MDPR}_{\max }$} & \multirow{2}{*}{$\begin{array}{l}\text { MDPR }_{\max } \text { vibratory } \\
\text { MDPR }_{\max } \text { venturi }\end{array}$} \\
\hline & Vibratory ${ }^{a}$ & Venturi ${ }^{\mathrm{b}}$ & \\
\hline Al $1100-0$ & $7.33 \pm 1.01$ & $0.621 \pm 0.50$ & 11.80 \\
\hline Al 2024-T-4 & $3.94 \pm 0.82$ & $0.193 \pm 0.14$ & 20.42 \\
\hline 1018 carbon steel & $0.54 \pm 0.01$ & 0.0182 & 29.67 \\
\hline 316 stainless steel & $0.24 \pm 0.01$ & $0.0133 \pm 0$ & 18.05 \\
\hline Cast iron $(3 \% \mathrm{C})$ & $0.53 \pm 0.02$ & $0.056 \pm 0.023$ & 9.46 \\
\hline Numerical average & & & $17.9_{-8.4}^{+11.8}$ \\
\hline
\end{tabular}

a $1.38 \times 10^{-3}$ in at 1 bar.

${ }^{b} V=49 \mathrm{~m} \mathrm{~s}^{-1}$.

\subsection{Temperature effect}

Substantial effects of water temperature on the MDPR and the IP exist in both facilities, even for these relatively small temperature variations. Previous vibratory tests $[1,2,11,12]$ indicate a maximum damage temperature for all materials and all liquids. The present results in both facilities are consistent with this expectation. Most of the vibratory tests indicate that for the three test temperatures $\left(80,160\right.$ and $\left.200{ }^{\circ} \mathrm{F}\right)$ the $\mathrm{MDPR}_{\max }$ occurred at $160^{\circ} \mathrm{F}$ (always at a $1 \mathrm{bar}$ suppression pressure). For the Venturi facility, the damage rate at $160^{\circ} \mathrm{F}$ was much larger than that at $80^{\circ} \mathrm{F}$ for both low velocity and high velocity. Figure 7 shows the effect of temperature on $\mathrm{MDPR}_{\max }$ for the vibratory facility, while Fig. 8 shows the effect of temperature for Venturi runs. The material used for both tests was 1018 carbon 


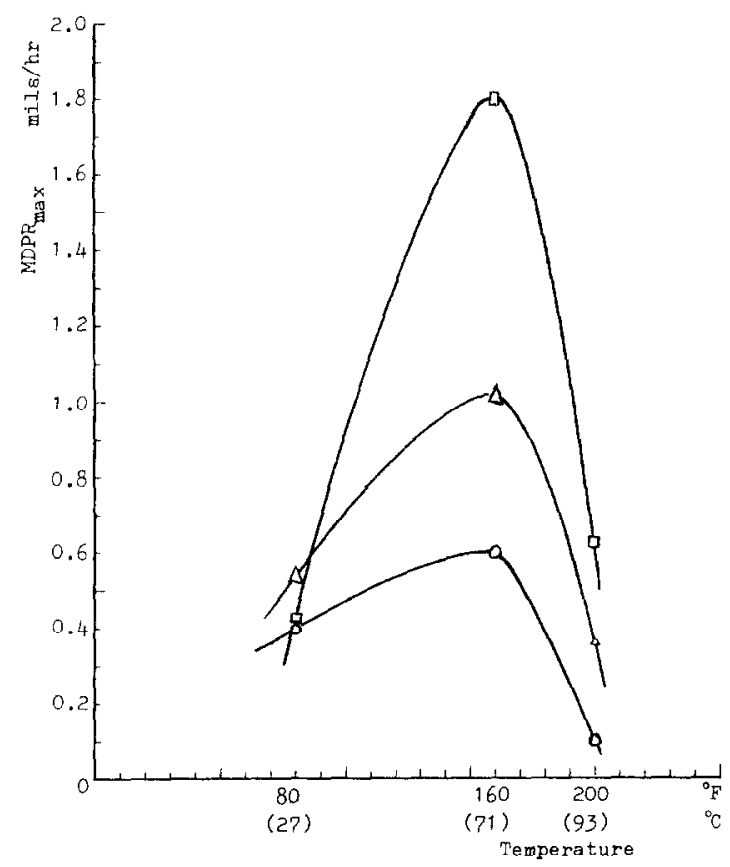

Fig. 7. The effect of temperature on $\mathrm{MDPR}_{\max }$ for 1018 carbon steel in vibratory cavitation erosion tests in fresh water at 1 bar: $\square, 1.78 \times 10^{-3} \mathrm{in} ; \triangle, 1.38 \times 10^{-3} \mathrm{in} ; \circ, 1 \times 10^{-3}$ in.

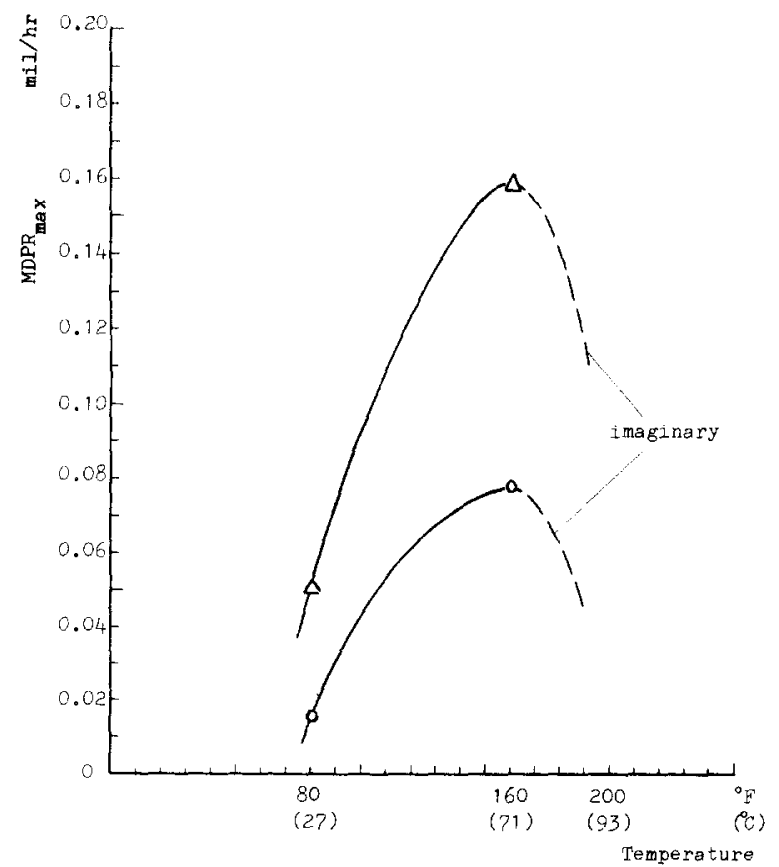

Fig. 8. A comparison of temperature effects on $M{ }^{2} R_{\max }$ for 1018 carbon steel Venturi tests at two velocities: $\triangle, V=36.3 \mathrm{~m} \mathrm{~s}^{-1}, K=0.73-0.76 ; \circ, V=49 \mathrm{~m} \mathrm{~s}^{-1}, K=0.62$. 0.64 . 
steel. No higher temperature Venturi tests have been made using the Plexiglas Venturi facility.

Figure 8 for the Venturi facility shows a negative velocity effect in that $M D P R_{\max }$ is greater for the lower velocity at both temperatures. As discussed elsewhere [10], this is presumably due to the reduced $\sigma(K)$ value at the higher velocity, even though the visually determined cavitation cloud termination point was the same for all tests. Thus a cavitation scale effect $[1,2]$ has been observed for this Venturi flow. Constant- $\sigma$ tests are now under way to resolve this apparent velocity paradox.

The substantial decrease in MDPR in the vibratory facility for a temperature above $160^{\circ} \mathrm{F}$, often observed previously $[1,2,11]$, is presumably due to cavitation "thermodynamic" effects, i.e. the increasing effect of vapor within the bubble in restraining bubble collapse. The usually smaller fall-off of MDPR toward lower temperatures is of less clear origin $[1,2]$ but may be due to changes in the properties of the liquid, e.g. increased viscosity.

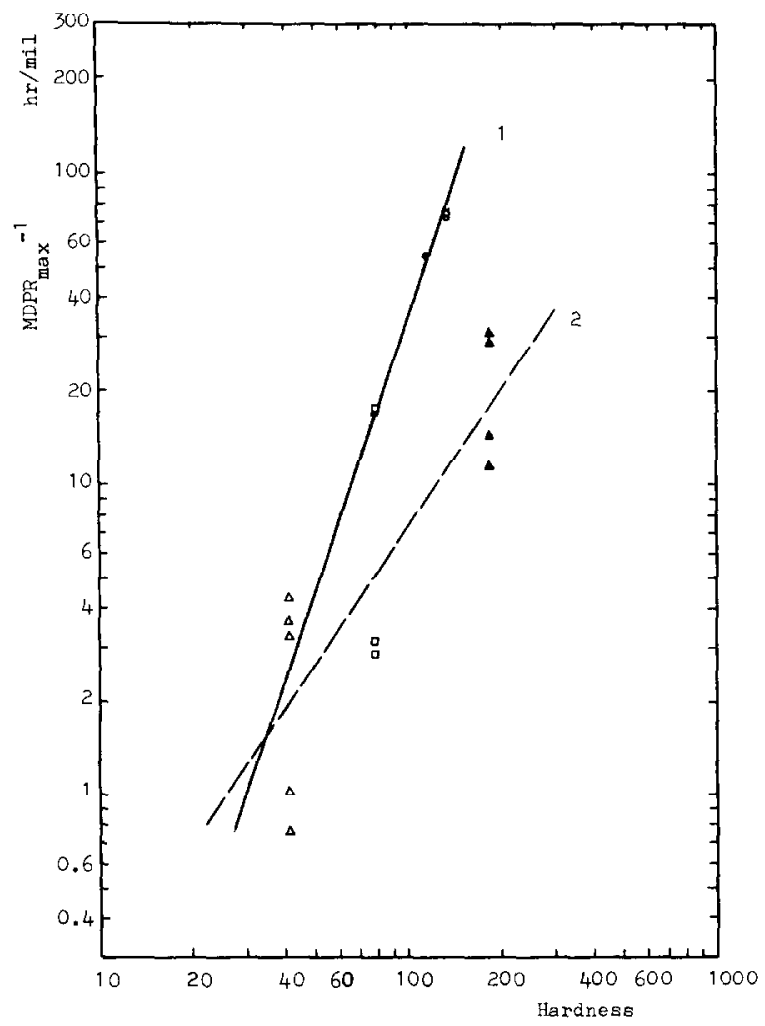

Fig. 9. $\mathrm{MDPR}_{\max }$ us. Brinell hardness $\left(\mathrm{MDPR}_{\max }{ }^{-1}=a H B^{n}\right)$ of materials for Venturi tests in fresh water at room temperature at a velocity of $49 \mathrm{~m} \mathrm{~s}^{-1}\left(160.8 \mathrm{ft} \mathrm{s}^{-1}\right):-, a=$ $3.96 \times 10^{-5}, n=2.97 ;---, a=8.40 \times 10^{-3}, n=1.47 ; \triangle$, Al 1100-0; $\square$, Al 2024-T-4; $\bullet, 1018$ carbon steel; $\circ, 316$ stainless steel; $\wedge$, cast iron $(3 \% \mathrm{C})$. 


\subsection{Brinell hardness results}

In Tables 2 - 5 the materials have been arranged according to their hardness $\mathrm{HB}$, starting with the aluminum alloys. Except for cast iron, $\mathrm{MDPR}_{\max }$ and IP change as expected with increasing hardness. However, the data cannot be well fitted to the expected relations

$$
\begin{aligned}
& \mathrm{MDPR}_{\text {max }}{ }^{-1}=a \mathrm{HB}^{n} \\
& \mathrm{IP}=a \mathrm{HB}^{n}
\end{aligned}
$$

for fixed test conditions. For the vibratory tests only three of these materials fit such relations in general, and the exponents scatter over a large range $(0.32-13.4)$, whereas the MDPR ratio is expected $[2,8]$ to be 2 and that for the IP is expected to be about the same.

The Venturi results are better. Four materials are suited roughly to these relations and the exponents are not so far from the expected mag. nitude of 2.0 ( $n=2.97$ and $n=3.56$ for the present tests). Figures 9 and 10 show the relationships between MDPR max $^{-1}$ and IP and the hardness of the materials for Venturi tests at $80^{\circ} \mathrm{F}$ at a velocity of $49 \mathrm{~m} \mathrm{~s}^{-1}$, while Figs. 11

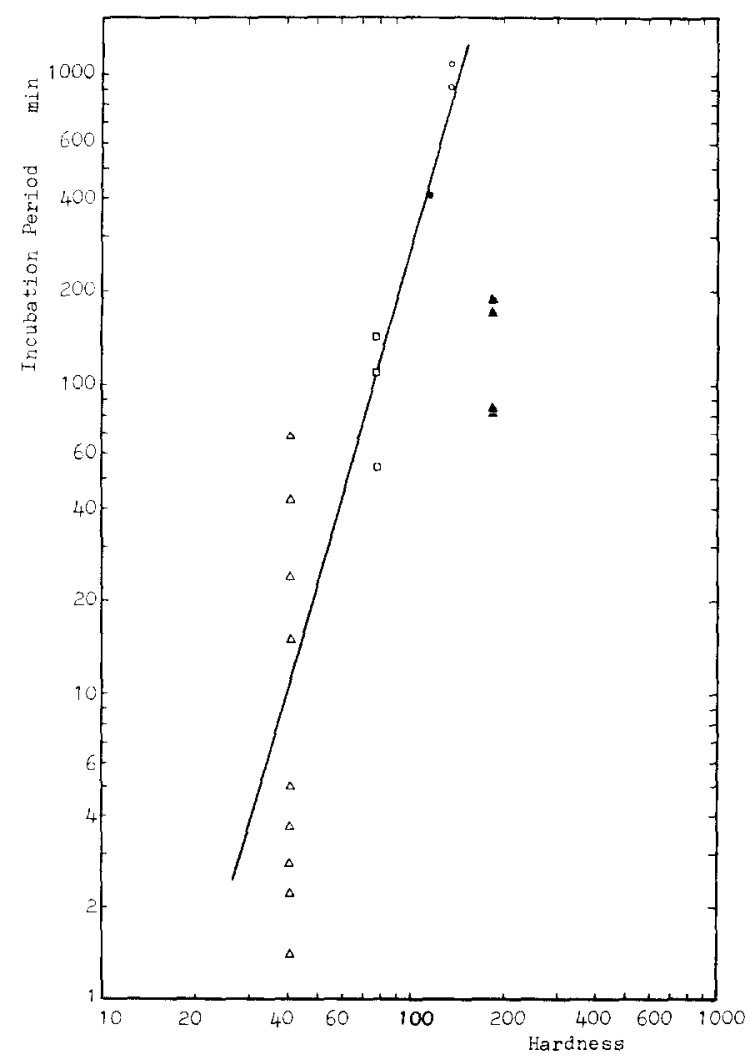

Fig. 10. IP vs. Brinell hardness (IP $=a \mathrm{HB}^{n}$ ) of materials in Venturi tests in fresh water at room temperature at a velocity of $49 \mathrm{~m} \mathrm{~s}^{-1}\left(160.8 \mathrm{ft} \mathrm{s}^{-1}\right): a=2.03 \times 10^{-5}, n=3.56 ; \triangle$, Al 1100-0; $\square$, Al 2024-T-4; $\bullet, 1018$ carbon steel; 0,316 stainless steel; $A$, cast iron ( $3 \% \mathrm{C})$. 


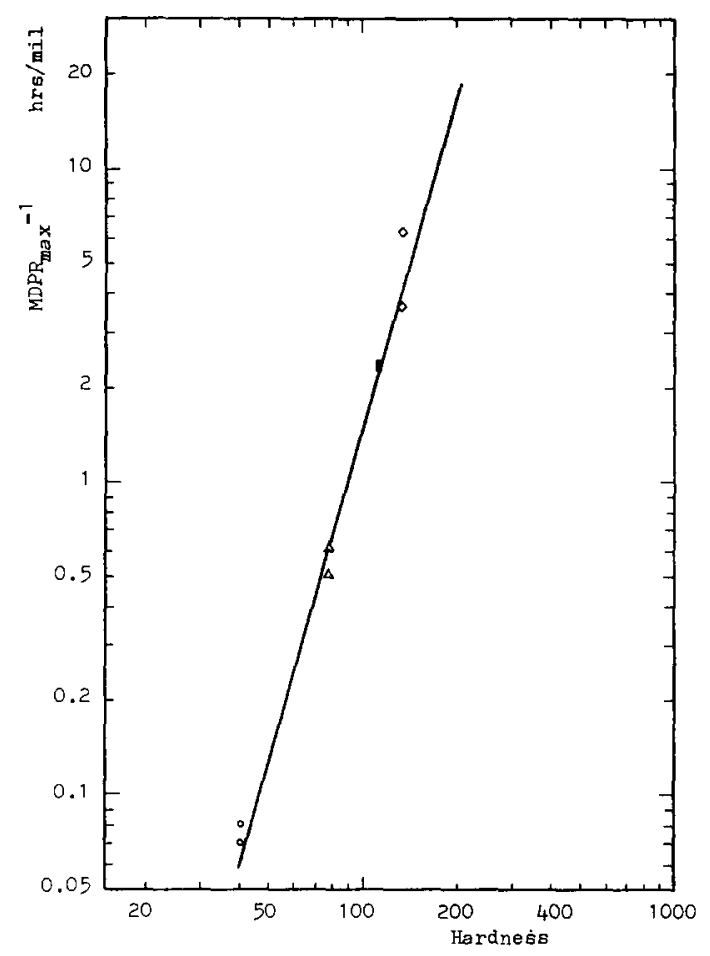

Fig. 11. $\mathrm{MDPR}_{\max }{ }^{-1}$ us. Brinell hardness $\left(\mathrm{MDPR}_{\max }{ }^{-1}=a \mathrm{HB}^{n}\right)$ of materials tested in vibratory cavitation erosion tests in fresh water at $80^{\circ} \mathrm{F}\left(27^{\circ} \mathrm{C}\right.$ ) (amplitude, $1.78 \times 10^{-3}$ in $(45.2 \mu \mathrm{m})): a=1.20 \times 10^{-7}, n=3.54 ; \circ, \mathrm{Al} 1100-0 ; \triangle$, Al 2024-T-4; $\bullet, 1018$ carbon steel; $\diamond, 316$ stainless steel.

and 12 are selected curves from the vibratory tests. Tables 10 and 11 contain the calculated exponents for comparing Venturi results with vibratory results. The exponent magnitudes are reasonably close, although those for the Venturi system are somewhat smaller, and reasonably close to expected results.

\subsection{Ultimate resilience correlations}

Much previous information $[1,2,11,12]$ indicates that the best correlation between cavitation (or liquid impingement) erosion and a single material property is found between $\mathrm{MDPR}_{\max }{ }^{-1}$ and ultimate resilience UR $\left(\mathrm{UR}=\mathrm{UTS}^{2} / 2 E\right)$, i.e. the volumetric material failure energy for brittle fracture often found with these phenomena. Logically, the exponent $n$ for the equation below should then be unity. Such results have sometimes been observed. Correlations with hardness are often nearly as good $[1,2,11,12]$ and a best-fit exponent of 1.85 for a very large data set has been reported $[2,11-13]$. Since UTS is often roughly proportional to hardness, it can be easily shown that the hardness exponent should then be 2 , reasonably close to the value of 1.85 observed previously [11 -13 ] 


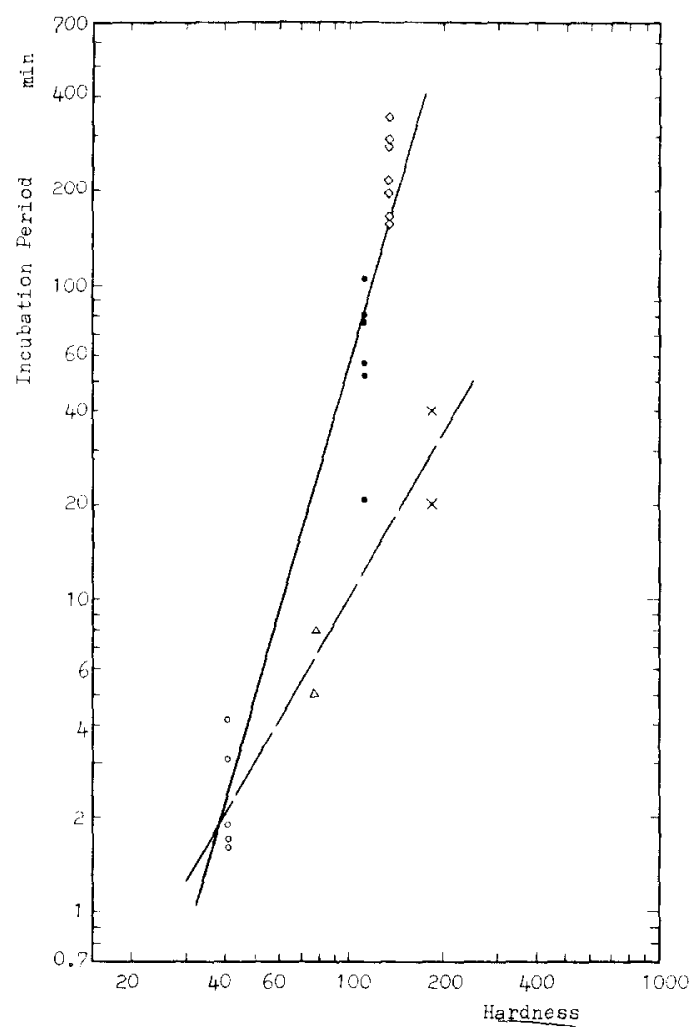

Fig. 12. IP vs. Brinell hardness (IP $\left.=a \mathrm{HB}^{n}\right)$ of materials tested for vibratory cavitation tests in fresh water at $80^{\circ} \mathrm{F}\left(27^{\circ} \mathrm{C}\right)$ (amplitude, $1 \times 10^{-3}$ in $\left.(25.4 \mu \mathrm{m})\right):-, a=2.61 \mathrm{x}$ $10^{-6}, n=3.70 ;---, a=3.10 \times 10^{-3}, n=1.76 ; \circ$, Al 1100-0; $\triangle$, Al 2024-T-4; $\bullet, 1018$ carbon steel; $\diamond, 316$ stainless steel; $x$, cast iron ( $3 \% \mathrm{C}$ ).

\section{TABLE 10}

A comparison of the exponents $n$ of the relation $\mathrm{MDPR}_{\max }{ }^{-1}=a \mathrm{HB}^{n}$

\begin{tabular}{lll}
\hline Material & Venturi run & Vibratory run \\
\hline $\left.\begin{array}{l}\text { Al } 1100-0 \\
\text { Al } 2024-\mathrm{T}-4 \\
1018 \text { carbon steel } \\
316 \text { stainless steel }\end{array}\right\}$ & & \\
$\begin{array}{l}\text { Al } 1100-0 \\
\text { Al } 2024-\mathrm{T}-4\end{array}$ & 2.97 & $3.54\left(1.78 \times 10^{-3} \mathrm{in}\right)$ \\
Cast iron $(3 \% \mathrm{C})$ & 1.47 & $1.83\left(1 \times 10^{-3}\right.$ in $)$ \\
\hline
\end{tabular}

The present Venturi results are more suitable and fit the UR correlation reasonably well, although the vibratory results are less successful. Except for Al 2024-T-4 the data can be combined in the relation 
TABLE 11

A comparison of the exponents $n$ of the relation $\mathrm{IP}=a \mathrm{HB}^{n}$

\begin{tabular}{llll}
\hline Material & Venturi run $^{\text {a }}$ & Material & Vibratory run $^{\mathrm{b}}$ \\
\hline $\left.\begin{array}{l}\text { Al 1100-0 } \\
1018 \text { carbon steel } \\
316 \text { stainless steel } \\
\text { Al 2024-T-4 }\end{array}\right\} \quad 3.56$ & $\left.\begin{array}{l}\text { Al 1100-0 } \\
1018 \text { carbon steel } \\
316 \text { stainless steel }\end{array}\right\} \quad 3.70\left(1 \times 10^{-3} \mathrm{in}\right)$ \\
& $\left.\begin{array}{l}\text { Al 1100-0 } \\
\text { Al 2024-T-4 } \\
\text { Cast iron }(3 \% \mathrm{C})\end{array}\right\}$ & $1.76\left(1 \times 10^{-3} \mathrm{in}\right)$ \\
\hline
\end{tabular}

a $V=49 \mathrm{~m} \mathrm{~s}^{-1} ; 80^{\circ} \mathrm{F}$.

b Amplitude, $1 \times 10^{-3}$ in; $80^{\circ} \mathrm{F}$.

$$
\mathrm{MDPR}_{\max }^{-1}=a \mathrm{UR}^{n}
$$

The value for the exponent $n$ of 1.15 is close to the expected value. Figure 13 is the Venturi curve and Fig. 14 is one of the vibratory curves for comparison. Table 12 contains the results for both facilities.

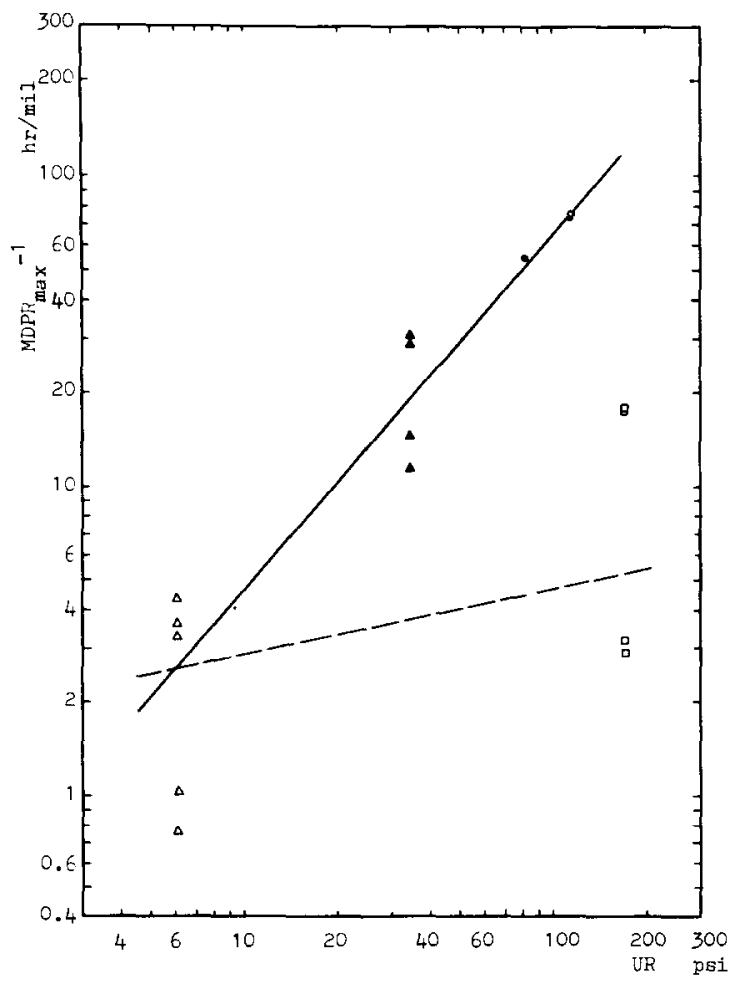

Fig. 13. $\mathrm{MDPR}_{\max }{ }^{-1}$ us. UR (MDPR $\left.{ }_{\max }^{-1}=a \mathrm{UR}^{n}\right)$ of materials in Venturi tests in fresh water at room temperature at a velocity of $49 \mathrm{~m} \mathrm{~s}^{-1}\left(160.8 \mathrm{ft} \mathrm{s}^{-1}\right):-, a=0.32, n=$ $1.15 ;---, a=1.80, n=0.21 ; \triangle$, Al $1100-0 ; \square$, Al $2024-\mathrm{T}-4 ; \bullet, 1018$ carbon steel; $\bigcirc, 316$ stainless steel; $\wedge$, cast iron. 


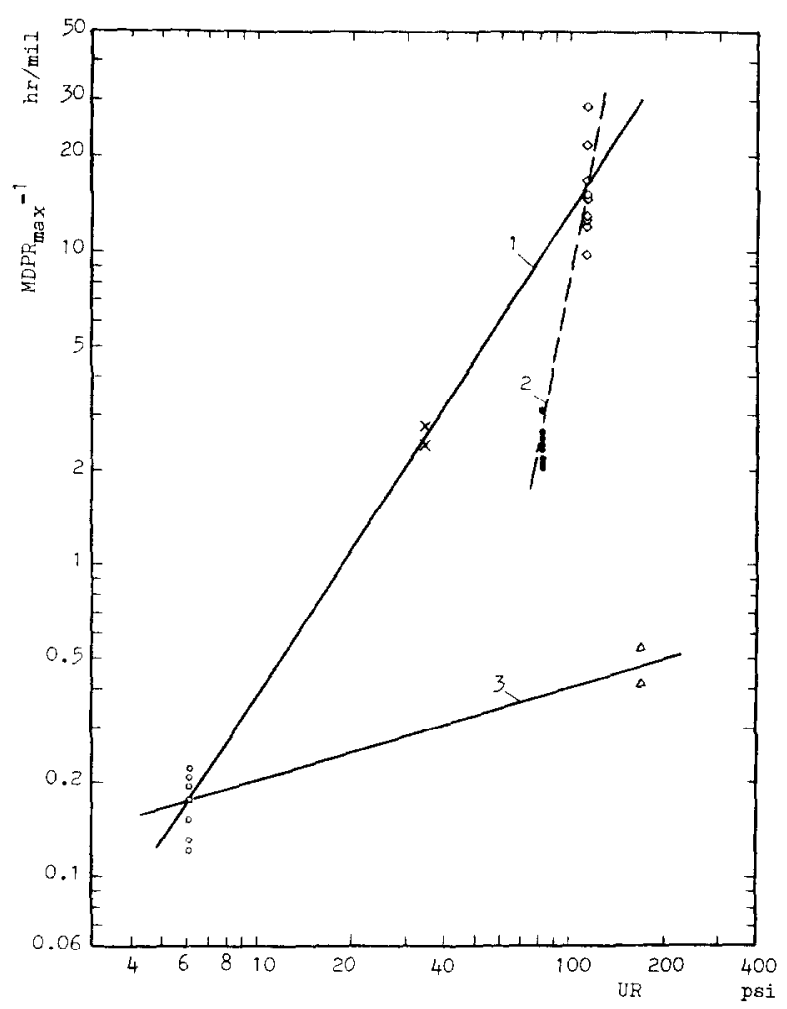

Fig. 14. $M D P R_{\max }{ }^{-1}$ us. UR (MDPR $\left.\max ^{-1}=a U R^{n}\right)$ of materials tested in vibratory cavitation erosion tests in fresh water at $80^{\circ} \mathrm{F}\left(27^{\circ} \mathrm{C}\right.$ ) (amplitude, $1 \times 10^{-3}$ in $(25.4 \mu \mathrm{m})$ ): curve $1, a=1.07 \times 10^{-2}, n=1.54$; curve $2, a=5.45 \times 10^{-11}, n=5.58 ;$ curve $3, a=8.97 \times$ $10^{-2}, n=0.32 ; 0$, Al 1100-0; $\triangle$, Al 2024-T-4; $\bullet, 1018$ carbon steel; $\diamond, 316$ stainless steel; $x$, cast iron $(3 \% \mathrm{C})$.

\section{TABLE 12}

A comparison of the exponents $n$ of the relation $\mathrm{MDPR}_{\max }{ }^{-1}=a \mathrm{UR}^{n}$

\begin{tabular}{|c|c|c|c|}
\hline Material & Venturi run ${ }^{\mathrm{a}}$ & Material & Vibratory run ${ }^{b}$ \\
\hline $\left.\begin{array}{l}\text { Al } 1100-0 \\
316 \text { stainless steel } \\
\text { Cast iron ( } 3 \% \text { C) } \\
1018 \text { carbon steel }\end{array}\right)$ & 1.15 & $\begin{array}{l}\text { Al } 1100-0 \\
316 \text { stainless steel } \\
\text { Cast iron }(3 \% \mathrm{C})\end{array}$ & $1.54\left(1 \times 10^{-3} \mathrm{in}\right)$ \\
\hline $\begin{array}{l}\text { Al } 1100-0 \\
\text { Al } 2024-\mathrm{T}-4\end{array}$ & 0.21 & $\begin{array}{l}\text { Al } 1100-0 \\
\text { Al } 2024-\mathrm{T}-4\end{array}$ & $\begin{array}{l}0.32\left(1 \times 10^{-3} \mathrm{in}\right) \\
0.18\left(1.38 \times 10^{-3} \mathrm{in}\right) \\
0.61\left(1.78 \times 10^{-3} \mathrm{in}\right)\end{array}$ \\
\hline
\end{tabular}

a $V=49 \mathrm{~m} \mathrm{~s}^{-1} ; 80^{\circ} \mathrm{F}$.

b $80{ }^{\circ} \mathrm{F}$.

The relation of IP to UR for both facilities is not well suited to a relationship of the form IP $=a U^{n}$, the exponents ranging from 1.3 to 2.4 
for combinations of three or more materials. Of course it should be realized $[2,11-13]$ that the factorial standard deviation for any erosion correlations is usually greater than about 3 .

\subsection{Incubation period and erosion rate correlations}

If the concept of a characteristic damage curve such as Fig. 3 is at all valid, then it should be possible to relate IP with MDPR $_{\max }$, as well as the time at which it should occur $[1,2,11]$. Such a development would be very useful, since it would then be possible to predict an eventual maximum erosion rate in the laboratory or field device from a measurement of an approximate IP alone; this is much more practical in many cases than measuring the entire erosion curve. Even though no exact characteristic curve like Fig. 3 exists for all materials, type of test, test conditions etc., these approximations can still be very valuable from an engineering viewpoint.

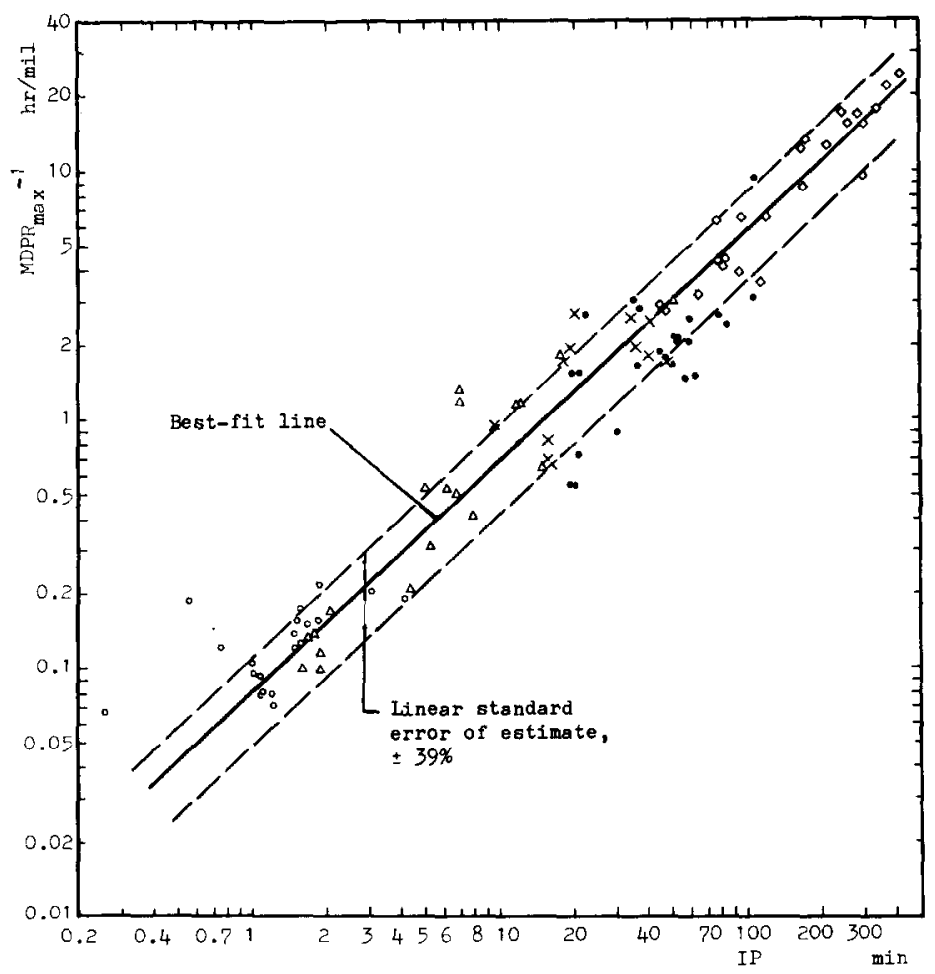

Fig. 15. Relationship between $M D P R_{\max }^{-1}$ and $I P\left(M D P R_{\max }{ }^{-1}=a I P^{n}\right)$ in vibratory cavitation erosion tests in fresh water at $80^{\circ} \mathrm{F}\left(27^{\circ} \mathrm{C}\right), 160^{\circ} \mathrm{F}\left(71^{\circ} \mathrm{C}\right)$ and $200^{\circ} \mathrm{F}\left(93^{\circ} \mathrm{C}\right)$ (amplitudes, $1 \times 10^{-3}$ in, $1.38 \times 10^{-3}$ in and $1.78 \times 10^{-3}$ in $(25.4 \mu \mathrm{m}, 35.1 \mu \mathrm{m}$ and $45.2 \mu \mathrm{m}$ respectively)): $a=8.01 \times 10^{-2}, n=0.93 ; \circ$, Al 1100-0; $\triangle$, Al 2024-T-4; $\bullet, 1018$ carbon steel; $\diamond, 316$ stainless steel; $x$, cast iron $(3 \% \mathrm{C})$. 


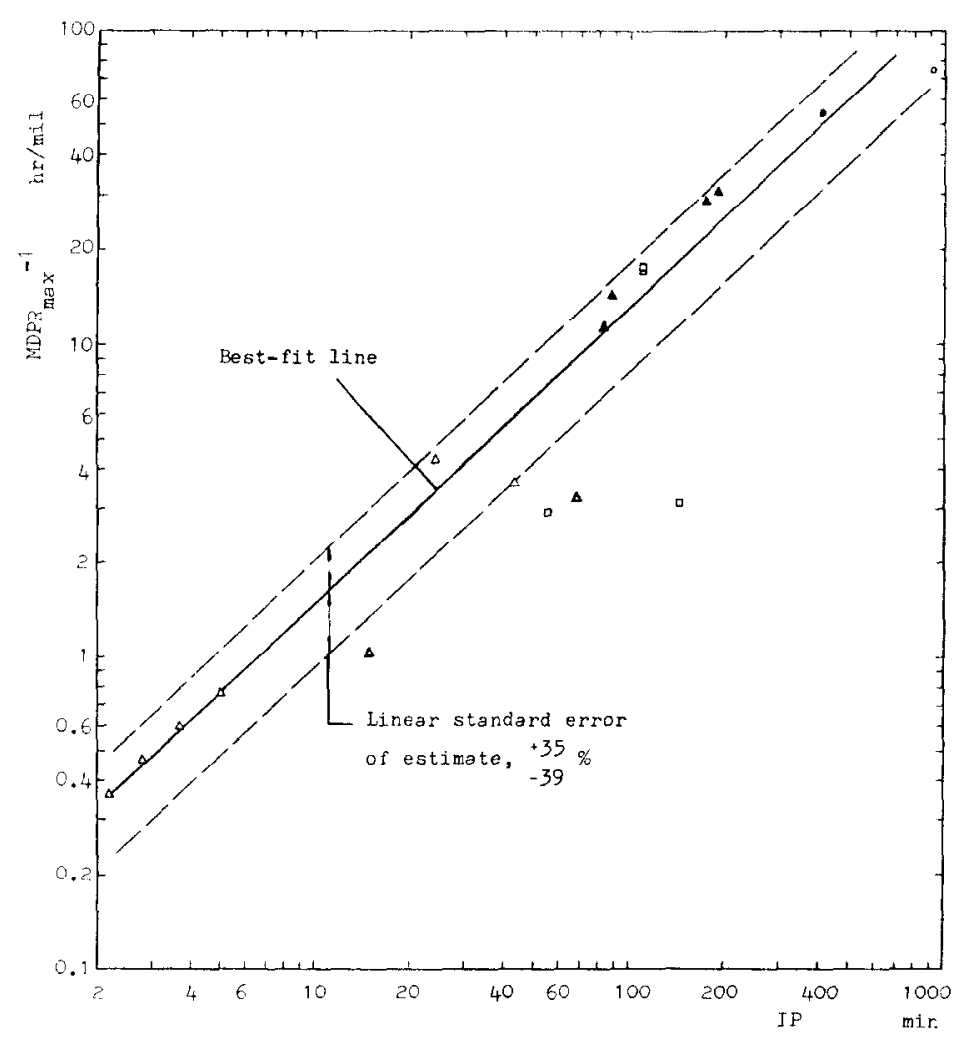

Fig. 16. The relationship between $\mathrm{MDPR}_{\max }{ }^{-1}$ and $\mathrm{IP}\left(\mathrm{MDPR}_{\max }{ }^{-1}=a \mathrm{IP}^{n}\right)$ in Venturi tests in fresh water at room temperature and a velocity of $49 \mathrm{~m} \mathrm{~s}^{-1}\left(160.8 \mathrm{ft} \mathrm{s}^{-1}\right): a=$ $0.17, n=0.95 ; \triangle, \mathrm{Al} 1100-0 ; \square, \mathrm{Al} 2024-\mathrm{T}-4 ; \bullet, 1018$ carbon steel; $\odot, 316$ stainless steel; $\triangle$, cast iron $(3 \% \mathrm{C})$.

It has often been assumed in the past $[2,11,12]$ that an approximate relation such as

$$
\mathrm{MDPR}_{\max }{ }^{-1}=a \mathrm{IP}^{n}
$$

can be used, where values of the amplitude constant and the exponents are found empirically. The present vibratory results fit this model very well (Fig. 15) for $n=0.93$. The correlation for the Venturi facility does not appear to be quite as good (Fig. 16), but the exponent is nearly the same $(n=0.95)$. In both cases the factorial standard deviation is less than $40 \%$. Previous tests $[2,11,12]$ have shown $0.7<n<1.2$. Hence, the present value $n=1$ is convenient but may not be generally valid.

For the soft Al 1100-0 Venturi tests, there was difficulty in estimating IP, since there existed an initial surge in weight loss. Hence IP values for $\mathrm{Al} 1100-0$ scattered over a large range. For vibratory tests 1018 carbon steel fitted the model least well, while for the Venturi tests 316 stainless steel was worst suited to the model. 


\section{Conclusions}

(1) A maximum damage rate temperature of $160{ }^{\circ} \mathrm{F}$ exists for vibratory cavitation erosion tests for all the materials tested. The Venturi results are consistent with this result, but the maximum damage temperature has not yet been established. It is probably above $160^{\circ} \mathrm{F}$.

(2) The IP shows a good correlation with the cavitation resistance $\mathrm{MDPR}_{\max }{ }^{-1}$ for both facilities. The exponent $n$ in the relation $\mathrm{MDPR}_{\max }{ }^{-1}=$ $a \mathrm{IP}^{n}$ is nearly unity $(0.93-0.95)$ for both facilities. The IP can then be used to estimate the eventual maximum erosion rate.

(3) The cavitation intensity as measured by $\mathrm{MDPR}_{\max }{ }^{-1}$ is $10-20$ times greater in the vibratory facility, depending on the horn amplitude and the test material. It is greatest (about 30) for 1018 carbon steel and least (about 5) for 316 stainless steel. This indicates important differences in form between the cavitation regimes in the two facilities, involving bubble sizes and collapsing pressures, beyond the obvious flow versus non-flow condition. It also indicates the imprecision of material comparisons made in either condition.

(4) General mechanical property correlations between the reciprocal erosion rate ("cavitation resistance"), $\mathrm{MDPR}_{\max }{ }^{-1}$ and either UR or HB for all materials tested do not exist for either facility. However, it is possible to combine four of the five materials to suit the relations $\mathrm{MDPR}_{\max }{ }^{-1}=a \mathrm{HB}^{n}$ or $\mathrm{MDPR}_{\max }{ }^{-1}=a U R^{n}$. The results are better for the Venturi facility.

(5) Soft (1100-0) aluminum, cast iron, 1018 carbon steel and 316 stainless steel can be combined to fit the UR model especially for Venturi tests, where the exponent is very close to unity, as theoretically expected ( $n=1.15$ for the present data set). Al 2024-T-4 does not fit such a correlation with the other materials.

(6) Materials which can be best grouped to fit the hardness model are $\mathrm{Al} \mathrm{1100-0}$ and $\mathrm{Al} \mathrm{2024-T-4}$ and 1018 carbon steel and 316 stainless steel, but the exponent $n$ of the relation MDPR ${ }_{\max }{ }^{-1}=a \mathrm{HR}^{n}$ is larger than expected ( $n$ ranges from 3 to 4 but should be about 2 theoretically). Cast iron does not fit this model.

\section{Acknowledgments}

Financial support for this work was provided by the Office of Naval Research Contract N00014-78-C-0697 and also internal University of Michigan Student Employment Program and Work Study funds.

\section{References}

1 F. G. Hammitt, Cavitation and Multiphase Flow Phenomena, McGraw-Hill, New York, 1980. 
2 R. T. Knapp, J. W. Daily and F. G. Hammitt, Cavitation, McGraw-Hill, New York, 1970.

3 F. G. Hammitt, Cavitation damage and performance research facilities. In G. M. Wood (ed.), Proc. ASME Symp. on Cavitation Research Facilities and Techniques, American Society of Mechanical Engineers, New York, 1964, pp. 175 - 184.

4 Standard method of vibratory cavitation erosion test, ANSI-ASTM Stand. G 32-77, 1977.

5 Alcoa Structural Handbook, Aluminum Company of America, Pittsburgh, PA, 1960.

6 Design and production. In C. Carmichael (ed.), Kent's Mechanical Engineer's Handbook, 12th edn., 1952.

7 F. G. Hammitt et al., ASTM G-2 cavitation round robin, Mater. Res. Stand., 10 (10) (1970) 19.

8. J.-g. He, A comparison of cavitation erosion test results from Venturi and vibratory facilities, DRDA Rep. UMICH 014456-72-I, February 1981 (University of Michigan, Ann Arbor, MI).

9 F. G. Hammitt, T. D. Helmholdt and M. K. De, Erosion of soft aluminum in cavitation Venturi, in Proc. ASME Cavitation and Polyphase Flow Forum, June 1979, American Society of Mechanical Engineers, New York, 1979, pp. $9-12$.

10 F. G. Hammitt, J.-g. He, G. Heinrich, C.-D. Hsu, V. Manoukian and B.-H. Sun, Cavitation erosion of ferrous and aluminum alloys in vibratory and Venturi facilities, in Proc. ASME Cavitation and Polyphase Flow Forum, June 1981, American Society of Mechanical Engineers, New York.

11 F. G. Hammitt, Cavitation and liquid impact erosion. In M. B. Peterson and W. O. Winer (eds.), Wear Control Handbook, American Society of Mechanical Engineers, New York, 1980, pp. 161 - 230.

12 F. G. Hammitt and F. J. Heymann, Liquid-erosion failures, in Metals Handbook, Vol. 10, American Society for Metals, Metals Park, OH, 8th edn., 1975, pp. 160 . 167.

13 F. J. Heymann, Erosion by cavitation or impingement, in ASTM Spec. Tech. Publ. 474,1970 , pp. $212 \cdot 248$. 